\title{
Contagem de reticulócitos de cães saudáveis ou anêmicos pela citometria de fluxo
}

[Count of reticulocyte counts of healthy or anemic dogs by flow cytometry]

\author{
P.M. Pereira ${ }^{1}$, M.C. Seki ${ }^{2}$, P.V.B. Palma ${ }^{3}$, F.R. Morais $^{3}$, A.E. Santana ${ }^{2}$, G.T. Pereira ${ }^{2}$ \\ ${ }^{1}$ Universidade Estadual de Londrina - Londrina, PR \\ ${ }^{2}$ Faculdade de Ciências Agrárias e Veterinárias - UNESP - Jaboticabal, SP \\ ${ }^{3}$ Faculdade de Medicina de Ribeirão Preto - USP - Ribeirão Preto, SP
}

\begin{abstract}
RESUMO
Compararam-se os resultados da contagem de reticulócitos pela microscopia de luz e pelo método da citometria de fluxo em 25 cães saudáveis (controle), 60 cães com anemia regenerativa e 40 com anemia arregenerativa. Houve diferença nas contagens absolutas obtidas pela microscopia de luz e pela citometria de fluxo nos três grupos estudados. A contagem de reticulócitos foi mais alta pela citometria de fluxo que a contagem pela microscopia de luz, mostrando ser um método mais sensível, simples e seguro para a quantificação de reticulócitos.
\end{abstract}

Palavras-chave: cão, citometria de fluxo, anemia, reticulócitos

\begin{abstract}
Counts of reticulocytes using both the light microscopy and flow cytometry (FC) methods in 25 healthy control dogs, 60 dogs with regenerative anemia, and 40 dogs with non-regenerative anemia were compared. The absolute counts were submitted to the paired t-Student test, which determined significant differences $(P<0.0001)$ between those methods in the three studied groups. Counts of retyculocytes were higher under flow cytometry, which proved to be a more sensitive method. Flow cytometry is a simple and reliable method for the quantification of reticulocytes.
\end{abstract}

Keywords: dog, flow cytometry, anemia, reticulocyte

\section{INTRODUÇÃO}

Reticulócitos são eritrócitos imaturos que contêm retículos com cadeias de RNA, mitocôndrias, ribossomos, centríolos e restos do complexo de Golgi (Cowgill et al., 2003). Após cerca de dois dias na medula óssea, os reticulócitos são normalmente liberados no sangue periférico para a maturação final (Riley et al., 2001).

A contagem de reticulócitos no sangue periférico informa sobre a atividade da medula óssea e a efetiva produção de eritrócitos (Nobes e Carter, 1990; Cowgill et al., 2003). Uma contagem de

Recebido em 21 de junho de 2007

Aceito em 31 de janeiro de 2008

Endereço para correspondência (corresponding address)

Rua Alexander Grahan Bell, 535/16 - 86063-250 - Londrina,

PR

E-mail: pmendes@uel.br

Apoio: FAPESP (Projeto 2003/00893-3) reticulócitos correta é muito importante para a classificação da anemia em regenerativa e arregenerativa e para o diagnóstico e prognóstico de várias doenças (Riley et al., 2001).

$\mathrm{O}$ aumento no número de reticulócitos circulantes (reticulocitemia) ocorre em pacientes anêmicos com medula óssea funcional, incluindo pacientes com perda de sangue e hemólise ou que estejam sendo tratados para outras causas de anemia. Contudo, pacientes anêmicos com desordens na medula óssea, eritropoiese deprimida ou diminuição da produção de eritropoietina podem apresentar contagem de reticulócitos normal ou diminuída 
(reticulocitopenia) (Nobes e Carter, 1990; Riley et al., 2001; Riley et al., 2002). Além da avaliação de pacientes anêmicos, a contagem de reticulócitos é também de grande valor na monitoração da atividade regenerativa da medula óssea após o uso de quimioterapia, drogas citotóxicas e transplantes no homem (Herkner, 1996; Riley et al., 2001; Riley et al., 2002; Cowgill et al., 2003).

Técnicas laboratoriais empregadas na contagem de reticulócitos estão fundamentadas na coloração do RNA ribossômico dos reticulócitos. De 1940 até início dos anos 80, a contagem de reticulócitos somente era realizada por esfregaços sangüíneos corados com corantes supravitais, como o novo azul de metileno ou azul brilhante de cresil, e leitura por meio da microscopia de luz (Nobes e Carter, 1990; Riley et al., 2002). Essa técnica ainda é o método mais usado para a contagem de reticulócitos no homem e em animais. O desenvolvimento de corantes fluorescentes específicos para RNA nos anos 80 propiciou o uso da citometria de fluxo na contagem de reticulócitos com aumento da sensibilidade e precisão (Donofrio et al., 1996; Tarallo et al., 1996; Riley et al., 2001; McCoy, 2002).

Vários fatores podem influenciar a reticulocitometria por microscopia de luz, dentre as quais citam-se as dificuldades técnicas na identificação dos reticulócitos, o tamanho da amostragem (total de células contadas: ideal 1.000 células, mínimo 500 células), tipo e qualidade do esfregaço sangüíneo, variação e qualidade da coloração, além, logicamente, do tempo gasto na análise das amostras e da baixa reprodutibilidade do método (Ferguson et al., 1990; Rowan et al., 1996; Nobes e Carter, 1990; Riley et al., 2001). A contagem de reticulócitos com o uso do citômetro de fluxo tem a vantagem de enumerar uma grande quantidade de células (10.000 a 50.000 células) em um curto espaço de tempo e com pouca variação de ordem técnica (Nobes e Carter, 1990; Brow e Wittwer, 2000; Riley et al., 2002). A maior desvantagem é a contagem superestimada de reticulócitos, causada por possível interferência de inclusões em eritrócitos, como os eritrócitos nucleados, os corpúsculos de Howell-Jolly, corpúsculo de Heinz e os parasitas intracelulares (Ferguson et al., 1990; Rowan et al., 1996; Brow e Wittwer, 2000; Riley et al., 2001). Uma grande variedade de fluorocromos pode ser usada na citometria de fluxo. Alguns exemplos são a acridina orange, tioflavina $\mathrm{T}$ e auramina. Entretanto, em meados dos anos 80, o thiazole orange (TO), um análogo da tioflavina $\mathrm{T}$, foi produzido especialmente para a contagem de reticulócitos feita pela citometria de fluxo (Riley et al., 2001; Riley et al., 2002), tornando-se o corante de eleição para reticulocitometria em cães (Weiss, 2002).

Valores de referência para reticulócitos, obtidos pela citometria de fluxo são importantes, pois, pela sua alta sensibilidade, há uma tendência de a contagem citofluorométrica ser, aproximadamente, 1,5 vezes maior que a contagem manual (Lacombe et al., 1999).

No homem, o intervalo de referência (média \pm desvio padrão) estabelecido e aceito por vários autores é de 1,69\% $\pm 0,52$ (Ferguson et al., 1990; Oosterhuis et al., 1992; Tarallo et al., 1996), porém outros laboratórios consideram o intervalo de 0,2 a 1,6\% (Nobes e Carter, 1990).

$\mathrm{Na}$ hematologia veterinária, há poucos trabalhos que usaram a citometria de fluxo para a contagem de reticulócitos, e não há referências de citação de valores normais e estudos de comparação entre os métodos de microscopia de luz e citometria de fluxo.

O objetivo deste ensaio foi comparar resultados da contagem de reticulócitos pela microscopia de luz e pelo método da citofluorometria em cães saudáveis e em cães com anemia regenerativa e arregenerativa.

\section{MATERIAL E MÉTODOS}

Avaliaram-se 125 cães, distribuídos em três grupos, sendo o grupo 1 (controle) constituído por 25 cães saudáveis e sem anemia, da raça Beagle; o grupo 2, por 60 cães com anemia regenerativa, identificados pela contagem de reticulócitos totais, pela microscopia de luz, acima de 60.000/ $\mu \mathrm{l}$; e o grupo 3, por 40 cães com anemia arregenerativa, identificados pela contagem de reticulócitos totais, pela microscopia de luz, abaixo de 60.000/ $\mu 1$.

O critério para inclusão dos cães no estudo foi a presença de anemia moderada a severa, volume globular abaixo de $26 \%$ e hemoglobina abaixo de $10 \mathrm{~g} / \mathrm{dl}$. O sangue foi colhido por venipunção da 
jugular com seringas a vácuo contendo etilenodiaminotetracetato dissódico (EDTA). O volume total de sangue colhido por animal, de aproximadamente $2 \mathrm{ml}$, foi armazenado à temperatura de $4^{\circ} \mathrm{C}$, por no máximo 48 horas (Cavill et al., 1996).

A contagem de reticulócitos em esfregaços sangüíneos por microscopia de luz foi realizada usando $100 \mu$ de sangue total incubado com azul brilhante de cresil $(100 \mu \mathrm{l})$ em banho-maria a $28^{\circ} \mathrm{C}$, por 15 minutos. Após a incubação, foi feito o esfregaço sangüíneo, contra-corado com uma mistura de May-Grunwald, giemsa e metanol. Realizaram-se as contagens de reticulócitos com o auxílio de objetiva de imersão (100X), sendo contadas 500 células. A contagem de reticulócitos por intermédio da citometria de fluxo foi realizada usando o fluorocromo thiazole orange (Retic-Count $\left.{ }^{\mathrm{TM}}\right)^{1}$, que penetra no reticulócito ligando-se ao RNA e fluorescendo os reticulócitos quando exposto ao laser. Foram usados dois tubos para o teste: um tubo-controle com $500 \mu \mathrm{l}$ de tampão fosfato salina isotônica, pH 7.4 e molaridade 0,01 (PBS), e um tubo-teste com $500 \mu \mathrm{l}$ do reagente tiazole orange. Em cada tubo foram colocados $5 \mu 1$ de sangue total com EDTA. Os tubos foram homogeneizados e incubados por 30 minutos, em temperatura ambiente, no escuro. Após esse período, foram submetidos à análise no citômetro de fluxo FACSORT, usando o software cellquest em que o número total de eventos adquiridos foi de 50.000 células para cada tubo (Fig. 1)
A

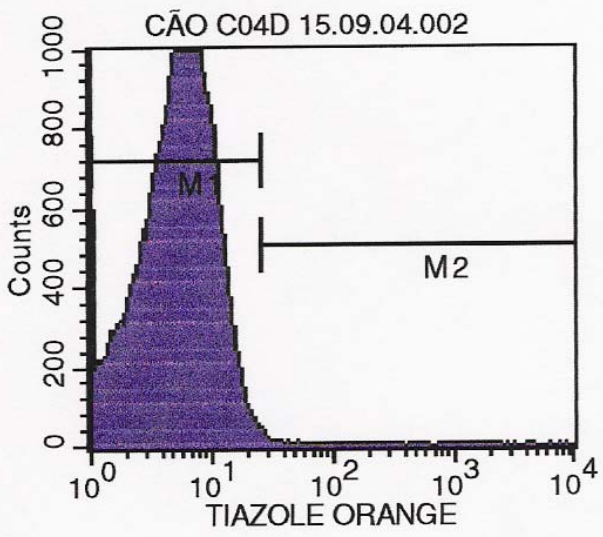

B

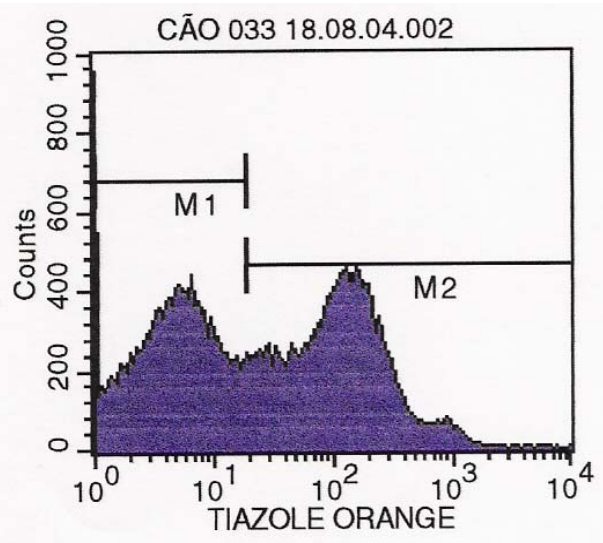

Figura 1. Quantificação de reticulócitos pela avaliação fluorométrica. Cão-controle (A) e cão com anemia regenerativa (B). Em A, a curva permanece em M1; em B, verifica-se um desvio da curva para a direita (M2), demonstrando a presença de marcação dos reticulócitos.

$\mathrm{Na}$ comparação dos grupos usou-se o teste $\mathrm{t}$ pareado. Obtiveram-se também as estatísticas descritivas conforme Massad (2004).

\section{RESULTADOS}

Os valores da citometria de fluxo foram mais altos $(\mathrm{P}<0,0001)$ que os da microscopia de luz em todos os grupos. As contagens totais de reticulócitos obtidas pela microscopia de luz e pela citometria de fluxo do grupo-controle variaram entre $21.030-258.160 / \mu 1$ e 83.628 $355.020 / \mu \mathrm{l}$ respectivamente. As médias das

${ }^{1}$ Becton Dickinson - San Jose, CA - EUA contagens foram de 95.963/ $\mu$ l (DP $\pm 58.316 / \mu 1$ $(\mathrm{CV}=60,7 \%)$ para microscopia de luz e de $203.994 / \mu \mathrm{l} \pm 67.684 / \mu \mathrm{l} \quad(\mathrm{CV}=33,1 \%) \quad$ para $\mathrm{a}$ citometria de fluxo. A contagem de reticulócitos pela citometria de fluxo foi, aproximadamente, quatro vezes mais alta que a contagem pela microscopia de luz ao se considerar o limite mais baixo das contagens, e apenas 1,4 mais alta ao se considerar o limite mais alto das contagens.

As contagens totais de reticulócitos obtidas pela microscopia de luz e pela citometria de fluxo do grupo de cães com anemia regenerativa variaram entre 61.400-1.680.000/ $\mu 1$ média $254.685 / \mu 1 \pm 305.916 / \mu 1$, e $76.043-2.013 .250 / \mu 1$, 
média de $335.280 / \mu 1 \pm 305.569 / \mu \mathrm{l}$; e do grupo de cães com anemia não regenerativa variaram entre $436-58.000 / \mu 1$, média de $26.000 / \mu 1 \pm 18.516 / \mu 1$, e 5.304-372.453 $\mu$ l, média de $89.368 / \mu 1 \pm 70.050 / \mu 1$ ), respectivamente. Os coeficientes de variação das contagens dos grupos anêmicos foram mais elevados que o da contagem do grupo-controle.

$\mathrm{Na}$ contagem de reticulócitos, todos os cães classificados como portadores de anemia regenerativa pela microscopia de luz também o foram pela citometria de fluxo. $\mathrm{O}$ mesmo não ocorreu nos cães com anemia não regenerativa, pois apenas $37 \%$ dos cães classificados como portadores de anemia pela microscopia de luz também o foram pela citometria de fluxo.

\section{DISCUSSÃO}

A contagem de reticulócitos é uma técnica essencial na investigação da atividade eritrocitária, e é muito importante que os resultados obtidos sejam confiáveis e precisos (Nobes e Carter, 1990).

No grupo de cães controle, os coeficientes de variação das contagens de reticulócitos obtidos pelos dois métodos foram mais altos que os observados no homem (Ferguson et al., 1990) ou mesmo em cães (Weiss, 2002). O grupo-controle usado neste estudo era composto por cães da raça Beagle, do mesmo canil, de ambos os sexos e idade variando de 1,3 a 3 anos, isto é, animais muito bem controlados. Mesmo com alto valor no coeficiente de variação, foi possível notar grande diferença entre os dois métodos utilizados, semelhante aos resultados já obtidos em estudos de hematologia no homem (Ferguson et al., 1990; Riley et al., 2001).

Segundo Buttarello et al. (2001) e Riley et al. (2001), existem ainda problemas quanto à diferença de sensibilidade dos corantes usados para corar o RNA dos reticulócitos, à tecnologia empregada para identificar células positivas e à sensibilidade do software em separar a população de células. Tudo isso resulta em contagens que, algumas vezes, diferem entre si quando realizadas por métodos diferentes, demonstrando a necessidade de se estabelecer valores de referências para cada método (Buttarello et al., 2001; Riley et al., 2001).
A variação na contagem de reticulócitos pode alterar a classificação, o diagnóstico e o tratamento da anemia, sendo importante a padronização dos valores de referências (Nobes e Carter, 1990; Buttarello et al., 2001). Neste estudo, as diferenças obtidas nas contagens de reticulócitos pelos dois métodos indicam a necessidade de se obter intervalo de referência específico para a citometria de fluxo, corroborando com ensaios anteriores (Buttarello et al., 2001; Riley et al., 2001). No homem, o intervalo estabelecido e aceito, por vários autores, é de 1,7\% 00,52 (Ferguson et al., 1990; Oosterhuis et al., 1992; Tarallo et al., 1996). Em cães não há, até o momento, nenhum valor bem definido para a contagem de reticulócitos na citometria de fluxo (Weiss, 2002).

Vários autores verificaram maior sensibilidade da citometria de fluxo em relação à microscopia de luz, principalmente quanto à baixa contagem de reticulócitos (Nobes e Carter, 1990; Buttarello et al., 2001; Weiss, 2002). Isto foi observado no presente estudo, em que a citometria de fluxo apresentou contagens mais altas que a microscopia de luz.

Estudos prévios com citometria de fluxo não analisaram a exatidão de níveis de reticulócitos abaixo do normal. Neste protocolo, ao classificar os tipos de anemia, observou-se maior sensibilidade da citometria de fluxo. Segundo Riley et al. (2001) e Weiss (2002), as contagens de reticulócitos pela citofluorometria correlacionam-se bem com a contagem $>2 \%$ obtida pela microscopia de luz, mas não se correlacionam com a contagem a $<2 \%$. Essas diferenças podem, não só estar relacionadas com a maior sensibilidade da contagem pela citometria de fluxo, como com possíveis interferências, como os corpúsculos de HowellJolly, o corpúsculo de Heinz e os parasitas intracelulares, que elevam a contagem dos reticulócitos. Isso pode ser sanado examinandose um esfregaço corado (Brow e Wittwer, 2000; Cowgill et al., 2003; Petz e Garratty, 2004).

Segundo Ferguson et al. (1990) e Oosterhuis et al. (1992), a correlação entre essas técnicas supracitadas em doadores de sangue é baixa. De acordo com Ferguson et al. (1990), isto é um reflexo do alto coeficiente de variação das contagens pela microscopia de luz. 
Conclui-se que a contagem de reticulócitos pela citometria de fluxo é um método simples, seguro e sensível para a quantificação de reticulócitos. $\mathrm{O}$ custo do aparelho ainda é um fator limitante. $\mathrm{O}$ uso da citometria de fluxo proporciona facilidades sobre a microscopia de luz, porém a padronização dos valores de referência e o estabelecimento dos controles positivo e negativo são necessários para a fixação da técnica na rotina da avaliação eritrométrica em cães.

\section{REFERÊNCIAS BIBLIOGRÁFICAS}

BROW M.; WITTWER, C. Flow cytometry: principles and clinical applications in hematology. Clin. Chem., v.46, p.1221-1229, 2000.

BUTTARELLO, M.; BULIAN, P.; FARINA, G. et al. Flow cytometric reticulocyte counting. Am. J. Clin. Pathol., v.115, p.100-111, 2001.

CAVILL, I.; KRAAIJENHAGEN, R.; PRADELLA, R. et al. In vitro stability of the reticulocyte count. Clin. Lab. Haematol., v.18, p.9-11, 1996.

COWGILL, E.S.; NEEL, J.A.; GRINDEM, C.B. Clinical application of reticulocyte counts in dogs and cats. Vet. Clin. Small Anim., v.33, p.1223-1244, 2003.

DONOFRIO, G.; KUSE, R.; FOURES, C. et al. Reticulocytes in haematological disorders. Clin. Lab. Haematol., v.18, p.29-34, 1996.

FERGUSON, D.J.; LEE S.F.; GORDON, P.A. Evaluation of reticulocyte counts by flow cytometry in a routine laboratory. Am. J. Hematol., v.33, p.13-17, 1990.

HERKNER, K.R. Clinical application of reticulocyte maturity grading in paediatrics: an overview. Clin. Lab. Haematol., v.18, p.55-59, 1996.
LACOMBE, F.; LACOSTE, L.; VIAL, J.P. et al. Automated reticulocyte counting and immature reticulocyte fraction measurement. Am. J. Clin. Pathol., v.112, p.677-686, 1999.

MASSAD, E. Métodos quantitativos em medicina. São Paulo: Manole, 2004. 561p.

McCOY, J.P. Basic principles of flow cytometry. Hematol. Oncol. Clin. N. Am., v.16, p.229-243, 2002.

NOBES, P.R.; CARTER, A.B. Reticulocyte counting using flow cytometry. J. Clin. Pathol., v.43, p.675-678, 1990.

OOSTERHUIS, W.P.; ZWINDERMAN, A.H.; MODDERMAN, T.A. et al. Multivariate statistical modeling: alternative approach to test evaluation, applied to counting reticulocytes by flow cytometry. Clin. Chem., v.38, p.1706-1711, 1992.

PETZ, L.D.; GARRATTY, G. The diagnosis of hemolytic anemia. In: PETZ, L.D.; GARRATTY, G. (Eds). Immune hemolytic anemias. 2.ed. Philadelphia: Churchill Livingstone, 2004. p.33-58.

RILEY, R.S.; BEN-EZRA, J.M.; GOEL, R. et al. Reticulocytes and reticulocyte enumeration, $J$. Clin. Lab. Anal., v.15, p.267-294, 2001.

RILEY, R.S.; BEN-EZRA, J.M.; TIDWELL, A. et al. Reticulocyte análisis by flow cytometry and other techniques. Hematol. Oncol. Clin. N. Am., v.16, p.373-420, 2002.

ROWAN, R.M.; CAVILL, I.; CORBERAND, J.X. The reticulocyte count: progress towards the resurrection of a useful clinical test. Clin. Lab. Haematol., v.18, p.3-8, 1996.

TARALLO, P.; HUMBERT, J.C.; FOURNIER, B. et al. Reticulocytes: reference limits. Clin. Lab. Haematol., v.18, p.13-14, 1996.

WEISS, D.J. Application of flow cytometric techniques to veterinary clinical hematology. Vet. Clin. Pathol., v.31, p.72-82, 2002. 